\title{
Economic issues in the use of office spirometry for lung health assessment
}

\author{
Murray Krahn MD MSc ${ }^{1}$, Kenneth R Chapman MD MSc${ }^{2}$
}

\begin{abstract}
M Krahn, KR Chapman. Economic issues in the use of office spirometry for lung health assessment. Can Respir J 2003;10(6):320-326.
\end{abstract}

The National Lung Health Education Program (United States) has recently recommended using office spirometry to screen for subclinical lung disease in adult smokers. No published studies evaluate the economic consequences of this recommendation. This review article outlines the issues that must be considered when evaluating the costs and health benefits of office spirometry. Much of the available data on the effectiveness of screening is from studies that included smoking cessation interventions, making it difficult to determine the effects of screening alone. The sensitivity and specificity of screening spirometry are not known, but may not be important in the economic model, because even false positive test results are beneficial if they lead to smoking cessation. Costs to be considered include those of spirometry itself, of implementing and maintaining screening and smoking cessation programs, and of their consequences, ie, reduced morbidity (lower short term health care costs) and mortality (perhaps higher long term health care costs). Despite these unique challenges, data are available to perform economic analyses regarding screening spirometry. Such analyses should play a role in future clinical policy making. Even modest quit rates attributable to screening spirometry may result in highly favourable cost effectiveness ratios.

Key Words: Cost effectiveness; Cost of illness; Economics; Pulmonary function tests; Screening; Spirometry

$\mathrm{U}$ sing spirometry to screen smokers for evidence of subclinical obstructive airways disease is intuitively appealing. Chronic obstructive pulmonary disease (COPD) incurs a large clinical and economic burden of illness. It is now the fourth leading cause of death in the United States, surpassed only by heart attacks, cancer and stroke. A similar number of individuals die from COPD per year $(n=100,000)$ (1) as from lung cancer $(n=119,000)$ and smoking-related cardiovascular disease $(n=180,000)(2)$. Smoking-related illness accounts for $6 \%$ of all direct health care expenditures in the United States; respiratory disease represents approximately one-third of this total $(1,3)$.

Furthermore, we know that spirometric testing is able to select those smokers who are at highest risk for developing COPD (4-6). We also know that smoking cessation is an effective means of preventing progression to clinical COPD. There

\section{Des enjeux économiques relativement à l'usage de la spirométrie en cabinet pour éval- uer la santé pulmonaire}

Le National Lung Health Education Program des États-Unis a récemment recommandé le recours à la spirométrie en cabinet pour dépister les maladies pulmonaires subcliniques chez les fumeurs adultes. Aucune étude publiée n'évalue les conséquences économiques de cette recommandation. Le présent exposé de synthèse indique les enjeux à envisager au moment d'évaluer les coûts et les bénéfices pour la santé de la spirométrie en cabinet. La plupart des données disponibles sur l'efficacité du dépistage proviennent d'études qui incluaient des interventions de renoncement au tabac, ce qui rend difficile la détermination des effets de la seule spirométrie. La sensibilité et la spécificité de la spirométrie de dépistage ne sont pas connues, mais elles ne revêtent peut-être pas d'importance dans le modèle économique parce que même de faux résultats positifs sont bénéfiques s'ils favorisent l'abandon du tabac. Les coûts à envisager sont ceux de la spirométrie elle-même, de l'implantation et du maintien du dépistage et du programme de renoncement au tabac, ainsi que de leurs conséquences, soit la diminution de la morbidité (frais de santé à court terme moins élevés) et de la mortalité (coûts de santé à long terme peutêtre plus élevés). Malgré ces défis uniques, il existe des données pour procéder à des analyses économiques de la spirométrie de dépistage. Ces analyses devraient jouer un rôle dans l'élaboration des futures politiques. Même un modeste taux de renoncement au tabac attribuable à la spirométrie de dépistage peut entraîner des rapports coût-efficacité hautement favorables.

is both observational $(5,7)$ and experimental (6) evidence suggesting that the rate of forced expiratory volume in $1 \mathrm{~s}\left(\mathrm{FEV}_{1}\right)$ decline and therefore the risk of progression to COPD is decreased in smokers who quit. The National Lung Health Education Program, on the basis of existing evidence, has launched an initiative to promote the use of office spirometry for screening in smokers older than the age of 45 years (8). The British Thoracic Society guidelines also suggest that smokers, particularly those with occupational risk, be screened (9). However, other specialty group guidelines $(10,11)$ and evidence-based guidelines put forward by the Canadian Task Force on the Periodic Health Examination (12), the American College of Physicians (13), the Agency for Health Care Policy and Research (14) and the American Thoracic Society (15) do not recommend that smokers be screened. Why the disagreement?

Departments of ${ }^{1}$ Medicine, ${ }^{2}$ Health Policy, Management and Evaluation, University of Toronto, Toronto, Ontario Correspondence: Dr M Krahn, The Toronto General Hospital, ENG-248, 200 Elizabeth Street, Toronto, Ontario M5G 2C4.

Telephone 416-340-4155, fax 416-595-5826, e-mail murray.krahn@uhn.on.ca 
One reason is cost. There are approximately $60,000,000$ smokers in the United States and Canada. At $\$ 20$ per test, screening would incur direct costs of over $\$ 1$ billion per episode. Follow-up visits, repeat office spirometry, full pulmonary function tests, lung imaging, drug prescriptions and smoking cessation interventions would follow initial office spirometry in many patients. Given current constraints on health expenditures, careful examination of the evidence for the effectiveness and cost effectiveness of screening spirometry is required before promulgation of clinical policies whose impact on aggregate health expenditures is so large. Highlighting the importance of this problem, a recent workshop sponsored by the National Heart, Lung, and Blood Institute in the United States indicated that the economics of smoking cessation, and in particular the cost effectiveness of screening for COPD, were key priorities in developing national research and prevention strategies for COPD (16).

How would one go about evaluating the economic attractiveness or 'cost effectiveness' of screening spirometry? Standard texts on economic evaluation in health care are available $(17,18)$. However, in this review we consider some of the unique issues in the design of an economic study of spirometric screening and then see how well the existing literature has addressed them.

\section{COMPARISONS}

Economic evaluations are usually comparative, and full evaluations are always so. Though a simple description of costs and consequences of a single program may be a useful contribution to knowledge, it is insufficient to allow a judgment about its economic attractiveness. An intervention is always more or less economically attractive in relation to some other program, even if the other program is 'no intervention'. Thus, screening spirometry will be more or less attractive in comparison with something else: either 'no intervention', 'usual care' or a smoking cessation program that does not incorporate screening spirometry.

Selection of either the intervention or the comparator(s) is not entirely straightforward. The intervention may be simple office spirometry or full pulmonary function testing. The intervention may be delivered to smokers who are presenting for periodic health examination, for respiratory complaints or for unrelated health problems. This type of 'screening' is often referred to as 'case finding' (15). The term 'screening' is usually reserved for population screening programs in which individuals are screened at a work site or other public site (eg, shopping mall), or are recruited to a central location through public advertisements. Population screening and case finding may differ in cost, efficacy, and evidentiary and ethical standards that must be met before implementation (15).

Attempts to define comparator and intervention are often complicated by the fact that individuals with abnormal spirometry results frequently receive additional interventions, whose effects are difficult to disentangle from the tests themselves. In the Lung Health Study (6), for example, all study participants received screening spirometry and a physiciandelivered, patient-specific message that the individual was at high risk for COPD. In addition, some patients received a multifaceted behavioural and pharmacological intervention targeted at smoking behaviour. The difference in quit rates between the two groups represented, therefore, is the aggregate effect of multiple factors.

Because most of the debate concerning the economics of screening spirometry has revolved around the screen itself, the incremental costs and health benefits of screening alone should be evaluated. Thus, both 'screening' and 'comparator' groups should receive the same behavioural and/or pharmacological antismoking interventions. Expert panels have issued guidelines suggesting that all smokers, not only those at high risk, should be targeted for antismoking interventions (14). Therefore, the value of screening spirometry should be judged by its ability to produce an increment above the quit rate observed in standard smoking cessation programs.

Alternatively, one may model a strategy that more closely mirrors clinical practice and that takes compliance with published guidelines into account. In clinical practice settings, smoking cessation efforts in unselected smokers may be modest. Abnormal spirometry tests may trigger more intensive, multifaceted and possibly effective smoking cessation efforts on the part of the physician and better compliance on the part of the patient. Whatever approach is chosen, the effects of the screen itself and the ancillary interventions that follow the screen must be kept conceptually distinct.

The population to whom the screening intervention is delivered must be considered. An unselected population including all smokers represents one option. Another option is to screen only those with cardiovascular risk factors such as diabetes, hypercholesterolemia or strong family history. Although this latter approach may seem a bit counterintuitive (ie, using cardiovascular risk factors to select patients for lung health screening), the health benefits per person who stops smoking will likely be proportionately greater, because the benefits of smoking cessation are primarily cardiovascular.

\section{STUDY ARCHITECTURE: MODELLING AND CLINICAL TRIALS}

There are two fundamentally different approaches to gathering and combining the cost and health benefit data in an economic evaluation. The first approach is to gather economic data simultaneously with clinical data in a randomized, controlled trial designed to evaluate the effectiveness of screening. In this 'piggyback' approach (19-21), the resource implications of gaining extra health benefits are computed directly from trial data at completion. The benefit of this approach is high internal validity of efficacy and cost estimates. A major drawback is the limited generalizability of trial results, particularly when practice patterns and costs are unrepresentative of community practice.

The other approach is to compare screening alternatives using decision analytical or simulation models $(22,23)$. In this approach, cost data and health data are gathered from disparate (usually secondary) sources and incorporated into a common model. Compared with a clinical trial, modelling allows the evaluation of many more alternatives and longer time horizons, but the comparisons between programs may be subject to greater bias.

Future economic studies of screening spirometry may adopt either approach. Because the Lung Health Study has provided 
a new legitimacy to the idea of screening smokers, a retrospective analysis using data from this study seems logical. However, this trial considered a single strategy that may not be widely generalizable, ie, a very intensive, multifaceted, behavioural and pharmacological smoking cessation strategy delivered over five years. It does not directly address the value of screening, but rather the effect of a complex intervention in a high risk group identified by screening. To determine the value of screening alone, the costs and health effects of a cohort of nonscreened smokers, as well as the cohort of screened smokers who were excluded from the trial, would also need to be considered. In addition, trial participants were highly unrepresentative of the general population. They volunteered to participate not only in a clinical trial, but also in an intensive smoking cessation program. Finally, additional modelling work would be required to fully assess the benefits of smoking cessation achieved in the Lung Health Study, because these extend over decades.

An alternative approach uses decision analytical or simulation models to consider the effects of screening spirometry in conjunction with a variety of smoking cessation interventions. A greater number of program alternatives, including ongoing or repeat screening and smoking cessation interventions that more closely mirror clinical practice, could be considered in an expeditious manner and at a reasonable cost.

\section{TEST PERFORMANCE CHARACTERISTICS}

Archie Cochrane, a British epidemiologist whose name graces the international research effort known as the Cochrane Collaboration, suggested that a good screening test should be simple, acceptable, reliable, valid, sensitive, specific and predictable (24). Office spirometry appears to meet most of these criteria. What about sensitivity and specificity?

First, any attempt to evaluate the operating characteristics of screening spirometry in the context of a full economic evaluation involves assumptions about the natural history of obstructive airways disease. We simply do not have data that directly describe the sensitivity and specificity of the test, ie, the probability of developing clinical obstructive airways disease given a particular $\mathrm{FEV}_{1}$ or $\mathrm{FEV}_{1}$ /forced vital capacity (FVC) result some decades earlier. The outcome measure for most prognostic studies in patients with early air flow obstruction, including the Lung Health Study, is the rate of decline in lung function, eg, $\mathrm{FEV}_{1}$ or $\mathrm{FEV}_{1} / \mathrm{FVC}$ ratio $(4,5,7,25,26)$. These represent secondary outcome measures, and the rates of occurrence of primary end points such as mortality and clinical obstructive airways disease can be predicted only using models of the natural history of disease.

One very simple approach to thinking about this problem would be to derive sensitivity and specificity values from a plot of $\mathrm{FEV}_{1} / \mathrm{FVC}$ versus rate of $\mathrm{FEV}_{1}$ loss. A positive test could be considered to be a $\mathrm{FEV}_{1} / \mathrm{FVC}$ ratio less than $70 \%$ to $75 \%$. Those who are 'disease positive' may be those with a rate of $\mathrm{FEV}_{1}$ loss greater than $50 \mathrm{~mL} /$ year or $75 \mathrm{~mL} /$ year. The sensitivity of the test could be described as the proportion of those with abnormal spirometry whose rate of $\mathrm{FEV}_{1}$ loss exceeds a preset threshold. Sensitivity analysis could evaluate the optimal threshold for screening spirometry.
This approach amounts to a restatement of the 'horse racing hypothesis', bruited about in the 1980s, which stated that those with abnormal spirometric results lose lung function more rapidly and are therefore at higher risk of obstructive airways disease than those with normal spirometry. Some evidence for this hypothesis was found in male, but not in female, smokers (4).

A more sophisticated approach would dispense with sensitivity and specificity entirely. The population of screenees and nonscreenees could be divided into multiple strata, characterized by a series of thresholds (of $\mathrm{FEV}_{1}$, for example). The annual probability of changing strata for smokers, nonsmokers and exsmokers would be modelled as a function of the mean rate of $\mathrm{FEV}_{1}$ loss, given smoking status and initial spirometric results. The rates at which primary endpoints (COPD, COPD-related death, non-COPD death) occur would be linked to a given threshold of pulmonary reserve $\left(\mathrm{eg}, \mathrm{FEV}_{1}\right)$. This approach relies on the conceptual model of the natural history of COPD first proposed by Fletcher and Peto (5). It implicitly incorporates the value of screening spirometry in two ways: spirometry would predict the rate of lung function loss and the remaining reserve at the time of screening. Thus, sensitivity and specificity are implicitly present and could be derived post hoc, but are not explicitly present as a variable in the model.

One insight about sensitivity and specificity that emerged from our early efforts to model the effects of screening spirometry, but has also been commented on by others $(27,28)$, is that sensitivity and specificity do not matter or, at least, they do not matter much. The consequences of any positive test, including a false positive test, are beneficial, because even smokers who are not truly at risk of COPD derive a large health benefit from quitting. These benefits include reduction in coronary heart disease and lung cancer incidence. Thus, sensitivity analyses in future economic evaluations will probably show that analytical results are not particularly sensitive to the screening threshold. They will likely also show that the optimal approach to setting thresholds for spirometric test abnormality is to call every single test in a smoker positive! This is a formal restatement of the idea of using screening spirometry simply as a stage prop (28). While similar to the inclination of some physicians to overinterpret spirometric results in an attempt to scare smokers into quitting, it breaches the ethical responsibility of physicians to tell the truth. Attempts, therefore, to derive screening thresholds in future studies will perhaps best be linked to the test's ability to separate patients on the basis of their pulmonary prognosis alone, rather than on the test threshold that results in the greatest overall health and economic benefit.

\section{EFFECTIVENESS}

Future analyses, however, are quite likely to be sensitive to the effectiveness of screening, expressed as the incremental quit rate in those who are screened relative to those who are not. What do we know about the effectiveness of screening spirometry? Not much - few randomized studies directly address the effect of screening spirometry on quit rates. Risser and Belcher (29) compared spirometry, carbon monoxide and symptom-related counselling with standard smoking cessation advice in 90 patients in a randomized trial at an outpatient general medicine clinic. Although multiple interventions were 
delivered, only one group received spirometric testing and results. At 12 months, the carbon monoxide-validated smoking cessation rate was $23 \%$ higher in the screened group than in the controls ( $33 \%$ versus $10 \%, \mathrm{P}=0.03$ ).

Segnan et al (30) randomized 923 smokers in primary care settings in Italy to counselling with spirometry, counselling alone and brief physician advice. The quit rates $(6.5 \%, 5.5 \%$ and $4.5 \%$, respectively) were not statistically significantly different. A population-based study in Norway (31) identified 2610 young men with a history of asbestos exposure and low $\mathrm{FEV}_{1}$ values. One-half of them were mailed a personal letter from their physician explaining their risk and advising them to stop smoking. In addition, the intervention group received a smoking cessation pamphlet. Crude quit rates were $5.6 \%$ and $3.5 \%$ in the intervention and nonintervention arms, respectively, a difference that remained statistically significant after adjustment for smoking intensity and asbestos exposure.

Nonrandomized studies show similarly heterogeneous results. Hepper et al (32) reported the results of a community lung screening program organized by the Minnesota Lung Association. The intervention consisted of advertising in selected communities, screening in a mobile van, advice to patients with abnormal results to see their physicians and a series of educational seminars for community physicians. The excess quit rate at two to three years in smokers with abnormal lung function was approximately $10 \%$ (32).

In the Lung Health Study, approximately $22 \%$ of the smoking intervention groups were sustained quitters at five years, compared with $5 \%$ in the usual care group (6). The excess quit rate is comparable with the $14 \%$ excess quit rate in smoking programs with more than two interventions reported in a meta-analysis of all smoking cessation interventions (33). However, the difference in quit rates in this study is due to the smoking intervention, not spirometry, because all patients received spirometry and were told of their abnormal results. The effect of spirometry alone appears less impressive when the $5 \%$ quit rate in the control group (who received spirometry) is compared with the expected $1 \%$ to $3 \%$ per year 'natural' quit rate among all smokers.

Given these scanty and heterogeneous data, it may be difficult to arrive at precise estimates of the incremental effectiveness of spirometry alone in future economic studies. Indeed, one recent evidence-based review suggested that there is no conclusive evidence that spirometry adds to the efficacy of standard smoking cessation advice.

We do not offer a summary judgment here about the state of the evidence. However, we make the following observations. First, screening spirometry must have some incremental benefit in improving quit rates for it to be justified as a rational health policy. Simply identifying smokers at high risk is a waste of resources unless it leads to improvement in health status. Such a strategy cannot be cost effective; cost effectiveness depends on effectiveness.

Second, even very modest quit rates, if they are in fact the consequence of spirometry, may be sufficient to render screening spirometry 'cost effective'. Published cost effectiveness analyses have shown that smoking cessation interventions with incremental quit rates of $3 \%$ to $6 \%$ are quite economically attractive despite their unimpressive effectiveness at first blush
(34-36). The reason why even modest quit rates are sufficient has to do with the very large health benefits associated with smoking. A small proportion of health benefit is attributable to reduction in obstructive airways disease. A much larger proportion of health benefit is attributable to reductions in coronary heart disease and lung cancer incidence rates.

Finally, there is the issue of emphasis. The recent special report of the National Lung Health Education Program (8) devotes pages of text to the issues of precision, reliability and calibration of office spirometers. The issue of what to do with abnormal results is not mentioned. For office spirometry to be effective and cost effective, it must be directly linked to specific, effective, preferably multifaceted smoking cessation interventions targeted to those at highest risk. Otherwise, purchasing, calibrating, maintaining and using office spirometers for screening is almost certainly a waste of time and resources.

In addition, a comprehensive economic evaluation must consider not only the intervention itself, but the effects on the case mix receiving the intervention. For example, referral of high risk smokers identified in a screening program to smoking cessation interventions may improve their aggregate health output by increasing the total number of smokers who quit, causing more high risk smokers to quit or both.

\section{COSTS}

Table 1 is a partial list of costs that should be included in a full economic evaluation of screening spirometry. The initial costs associated with screening include not only the costs of the intervention itself, but also the costs associated with program infrastructure and advertising, and induced costs related to more intensive medical care in screenees. These costs are very frequently excluded in analyses of screening programs (37).

Little has been published about the overall costs of screening spirometry. Owens (38) estimated the costs of recruitment in the Lung Health Study (ie, screening and other trial costs excluded) to be US $\$ 14$ per abnormal result in work sites and public sites. Costs for radio, direct mail and newspaper advertising were approximately US $\$ 150$ per abnormal result, and costs for advertising on public transit increased to US $\$ 778$ per abnormal result (38).

Better information is available about downstream costs. The economic consequences of smoking have been described in numerous reviews (2,39-41). Most of this information, however, is not directly applicable to a screening population, because the effects of screening are largely seen only in high risk smokers, ie, those with abnormal test results. Short term health expenditures are likely be higher than among all smokers and long term expenditures probably lower due to higher mortality rates. The net effect is difficult to predict in the absence of modelling.

Some limited cost data on caring for COPD patients are available (42-48), but future studies may require additional empirical costing work to accurately predict the long term economic effects of spirometric screening.

\section{HEALTH EFFECTS}

Table 2 is a partial list of health effects induced and averted by spirometric screening. The short term psychological effects of screening in other clinical contexts are real but dif- 
TABLE 1

Costs in chronic obstructive pulmonary disease (COPD) screening

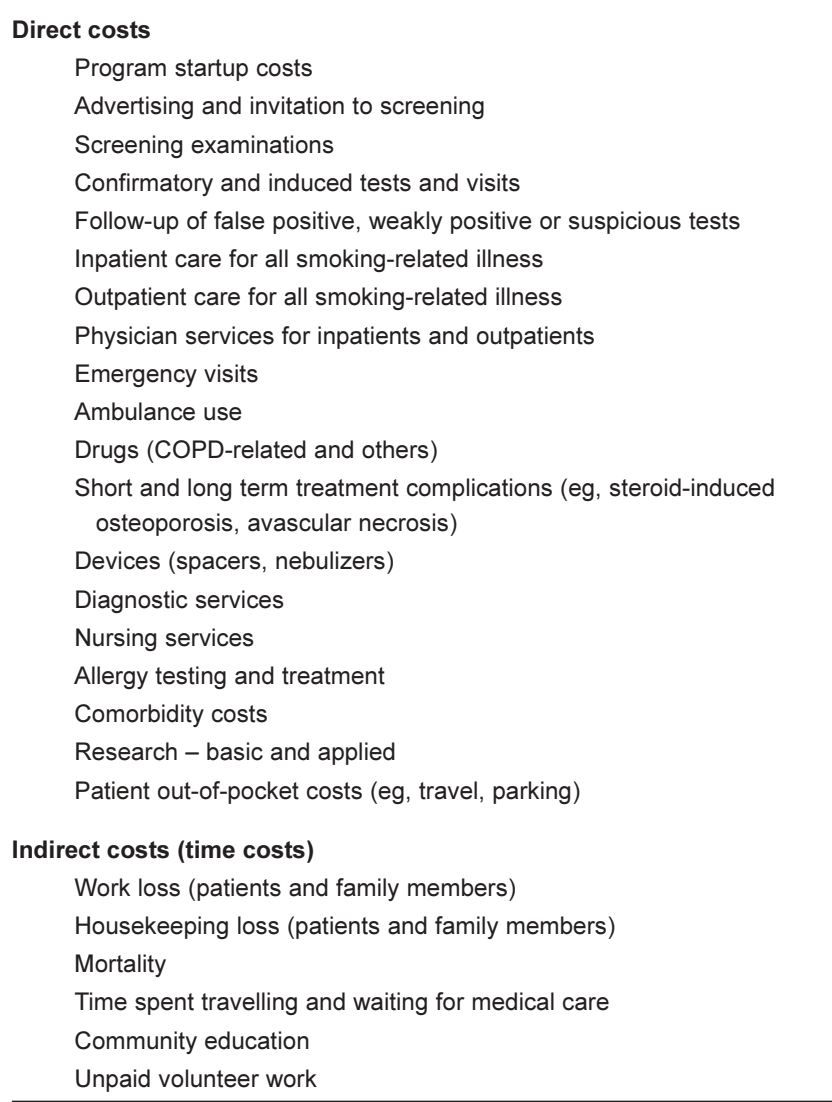

ficult to measure and of variable magnitude. Labelling, for example, has been shown to adversely affect hypertensive (49) but not hypercholesterolemic patients $(50,51)$. Anxiety has been shown to be induced by screening mammography and genetic screening for breast cancer $(52-54)$, and it can reduce compliance in ongoing screening programs (52-54). Although no empirical data on the effects of labelling and anxiety around screening spirometry have yet been published, the diagnosis of 'obstructive airways disease' may carry less emotional freight than that of 'cancer'. Even if short term psychological effects exist, measuring them in a way suitable for use in an economic evaluation would not be straightforward. Neither generic (52-58) nor disease-specific (59-62) utility instruments have been used for this purpose in other screening contexts, most likely because they are insufficiently responsive to detect psychological effects of low magnitude. Most economic evaluations of cancer screening programs do not include adverse psychological effects of screening. Nonetheless, because the effects of spirometric screening are distributed across every screenee, whereas the benefits accrue only to those with positive tests who actually stop smoking ( $0 \%$ to $2 \%$ overall), the short term effects of screening are quantitatively important and should be carefully considered in future evaluations. Downstream quality of life effects, including those attributable to prevention of coronary heart disease and lung cancer, are of larger magnitude
TABLE 2

Health effects in chronic obstructive pulmonary disease screening

Screening
Effects of screen itself (physical discomfort)
Labelling; anxiety related to diagnosis
Anxiety in patients with false positive or indeterminate test results
False reassurance in smokers with normal results
Discomfort of induced tests (x-rays, pulmonary function tests)
Treatment
Short term discomfort associated with smoking cessation
Morbidity averted by preventing:
- Cardiovascular disease
- Obstructive airways disease
Mortality averted by preventing:
- Cardiovascular disease
- Obstructive airways disease
- Cancer
Improved sense of well-being

and have been assessed with generic utility instruments $(35,57)$. An alternate approach excludes all quality of life considerations and focuses only on the mortality benefits of screening in a cost-benefit or cost effectiveness (cost per year of life saved) analysis. This much simpler but less comprehensive approach is often taken in screening studies in other contexts (63-66) and in economic analyses of smoking cessation strategies $(34,35)$.

\section{ECONOMIC EVALUATION OF SPIROMETRIC SCREENING}

In the only published economic evaluation of lung function testing, Loss et al (67) screened 73 young smokers, $75 \%$ of whom had abnormal pulmonary function test results. At six months, $7 \%$ of those with abnormal tests had quit smoking. The cost per incremental quitter was estimated to be US $\$ 1392$. No control group was assessed, and the long term health and economic effects of smoking cessation were not considered. This result is therefore of marginal value in policy formulation.

\section{CONCLUSIONS}

Although spirometry is relatively inexpensive, the aggregate economic and health effects of testing all smokers are large. Economic studies should play a role in future clinical policy formulation regarding the role of screening spirometry. Although economic studies in this area face some unique challenges, good quality cost and outcome data are available for many components of the problem. Several good quality economic analyses of smoking cessation programs (34-36) could provide a template to researchers beginning to design economic analyses of screening spirometry. As these studies suggest, even modest incremental quit rates could show screening spirometry to be quite cost effective.

ACKNOWLEDGEMENTS: Support for this project was provided by an unrestricted grant from Boehringer-Ingelheim. 


\section{REFERENCES}

1. Kronebusch K. Smoking: Human and economic costs. Cancer Invest 1989;7:463-77.

2. Bartecchi CE, MacKenzie TD, Schrier RW. The human costs of tobacco use. N Engl J Med 1994;330:907-12.

3. Leigh JP, Romano PS, Schenker MB, Kreiss K. Costs of occupational COPD and asthma. Chest 2002;121:264-72.

4. Burrows B, Knudson RJ, Camilli AE, Lyle SK. The "horse-racing effect" and predicting decline in forced expiratory volume in one second from screening spirometry. Am Rev Respir Dis 1987;135:788-93.

5. Fletcher C, Peto R. The natural history of chronic airflow obstruction. BMJ 1977;i:1645-8.

6. Anthonisen NR, Connett JE, Kiley JP, et al. Effects of smoking intervention and the use of an inhaled anticholinergic bronchodilator on the rate of decline of $\mathrm{FEV}_{1}$. JAMA 1994;272:1497-505.

7. Camilli AE, Burrows B, Knudson RJ, Lyle SK, Lebowitz MD. Longitudinal changes in forced expiratory volume in one second in adults. Am Rev Respir Dis 1987;135:794-9.

8. Ferguson GT, Enright PL, Buist AS, Higgins MW. Office spirometry for lung health assessment in adults: A consensus statement from the National Lung Health Education Program. Respir Care 2000;45:513-30.

9. BTS guidelines for the management of chronic obstructive pulmonary disease. The COPD Guidelines Group of the Standards of Care Committee of the BTS. Thorax 1997;52(Suppl 5):S1-28.

10. Standards for the diagnosis and care of patients with chronic obstructive pulmonary disease. American Thoracic Society. Am J Respir Crit Care Med 1995;152:S77-121.

11. Siafakas NM, Vermiere P, Pride NB, et al. Optimal assessment and management of chronic obstructive pulmonary disease (COPD). The European Respiratory Society Task Force. Eur Respir J $1995 ; 8: 1398-420$.

12. The Canadian Task Force on the Periodic Health Examination. The Canadian Guide to Clinical Perspective Health Care. Ottawa: Ministry of Supply and Services, 1994.

12. Sox HC. Current concepts. Preventive health services in adults. N Engl J Med 1994;330:1589-95.

14. The Agency for Health Care Policy and Research Smoking Cessation Clinical Practice Guideline. JAMA 1996;275:1270-80.

15. Screening for adult respiratory disease. Official American Thoracic Society statement. Am Rev Respir Dis 1983;128:768-74.

16. Petty TL, Weinmann GG. Building a national strategy for the prevention and management of and research in chronic obstructive pulmonary disease. JAMA 1997;277:246-53.

17. Gold MR, Siegel JE, Russell LB, Weinstein MC, eds. Cost Effectiveness in Health and Medicine. New York: Oxford University Press, 1996.

18. Drummond MF, O'Brien B, Stoddart GL, Torrance GW. Methods for the economic evaluation of health care programmes. New York: Oxford University Press, 1997.

19. Ramsey SD, McIntosh M, Sullivan SD. Design issues for conducting cost effectiveness analyses alongside clinical trials. Annu Rev Public Health 2001;22:129-41.

20. O'Hagan A, Stevens JW, Montmartin J. Bayesian cost effectiveness analysis from clinical trial data. Stat Med 2001;20:733-53.

21. Dixon S, Deverill M, Gannon M, Brazier J, Haggard M. Improving the validity of economic evaluations alongside controlled trials. J Health Serv Res Policy 1999;4:161-3.

22. Krahn M, Guasparini R, Sherman M, Detsky AS. Costs and cost effectiveness of a universal, school-based, adolescent hepatitis B vaccination program. Am J Public Health 1998;88:1638-44.

23. Wong JB, Nevens F. Cost effectiveness of peginterferon alfa-2b plus ribavirin compared to interferon alfa-2b plus ribavirin as initial treatment of chronic hepatitis C in Belgium. Acta Gastroenterol Belg 2002;65:110-1.

24. Cochrane A, Holland WW. Validation of screening programmes. Br Med Bull 1971;27:3-8.

25. Bosse R, Sparrow D, Rose CL, Weiss ST. Longitudinal effect of age and smoking cessation on pulmonary function. Am Rev Respir Dis 1981;123:378-81.

26. Detels R, Sayre JW, Tashkin DP, Massey FJ, Coulson AH, Rokaw SN. The UCLA population studies of chronic obstructive respiratory disease. VI. Relationship of physiologic factors to rate of change in forced expiratory volume in one second and forced vital capacity. Am Rev Respir Dis 1984;129:533-7.
27. O'Hagan J. Prevention of chronic obstructive pulmonary disease: A challenge for the health professions. N Z Med J 1996;109:1-2.

28. Freedman S, Raffin TA, Rothkopf MH, Eddy DM. The value of a stage prop: Screening for chronic obstructive pulmonary disease. Chest 1984;85:406-7.

29. Risser NL, Belcher DW. Adding spirometry, carbon monoxide, and pulmonary symptom results to smoking cessation counseling: A randomized trial. J Gen Intern Med 1990;5:16-22.

30. Segnan N, Ponti A, Battista RN, et al. A randomized trial of smoking cessation interventions in general practice in Italy. Cancer Causes Control 1991;2:239-46.

31. Humerfelt S, Eide GE, Kvale G, Aaro LE, Gulsvik A. Effectiveness of postal smoking cessation advice: A randomized controlled trial in young men with reduced $\mathrm{FEV}_{1}$ and asbestos exposure. Eur Respir J 1998;11:284-90.

32. Hepper NGG, Drage CW, Davies SF, et al. Chronic obstructive pulmonary disease: A community oriented program including professional education and screening by a voluntary health agency. Am Rev Respir Dis 1980;121:97-104.

33. Kottke TE, Battista RN, DeFriese GH, Brekke ML. Attributes of successful smoking cessation interventions in medical practice. JAMA 1988;259:2882-9.

34. Oster G, Huse DM, Delea TE, Colditz GA. Cost effectiveness of nicotine gum as an adjunct to physician's advice against cigarette smoking. JAMA 1986;256:1315-8.

35. Fiscella K, Franks P. Cost effectiveness of the transdermal nicotine patch as an adjunct to physicians' smoking cessation counselling. JAMA 1996;275:1247-51.

36. Cummings SR, Rubin SM, Oster G. The cost effectiveness of counselling smokers to quit. JAMA 1989;261:75-9.

37. Krahn M, Naglie G. Principles of economic evaluation in cancer screening programs. In: Miller AB, ed. Advances in Cancer Screening. New York: Kluwer Academic Publishers, 1996:25-40.

38. Owens GR. Public screening for lung health disease: Experience with the Lung Health Study. Am J Med 1991;91(Suppl 4A):37S-40S.

39. Barendregt JJ, Bonneux L, Van der Maas PJ. The health care costs of smoking. N Engl J Med 1997;337:1052-7.

40. MacKenzie TD, Bartecchi CE, Schrier RW. The human costs of tobacco use. N Engl J Med 1994;330:975-80.

41. Hodgson TA. Cigarette smoking and lifetime medical expenditures. Milbank Q 1992;70:81-125.

42. Bergner M, Hudson LD, Conrad DA, et al. The cost and efficacy of home care for patients with chronic lung disease. Med Care 1988;26:566-79.

43. Strauss MJ, Conrad D, LoGerfo JP, Hudson LD, Bergner M. Cost and outcome of care for patients with chronic obstructive lung disease. Analysis by physician specialty. Med Care 1986;24:915-24.

44. Toeversus CD, Kaplan RM, Atkins CJ. The costs and effects of behavioral programs in chronic obstructive pulmonary disease. Med Care 1984;22:1088-100.

45. Miravitlles M, Murio C, Guerrero T, Gisbert R. Pharmacoeconomic evaluation of acute exacerbations of chronic bronchitis and COPD. Chest 2002;121:1449-55.

46. Gallefoss F, Bakket PS. Cost-benefit and cost effectiveness analysis of self-management in patients with COPD - a 1-year follow-up randomized, controlled trial. Respir Med 2002;96:424-31.

47. Gordois A, Scuffham P, Gibbons D. The cost effectiveness of outreach respiratory care for COPD patients. Prof Nurse 2002;17:504-7.

48. Taylor C, Gardner B, Heslop L, Lowe E, Habner M, Athan D. Identification of factors contributing to increased length of stay in two diagnosis related groups. Aust Health Rev 2001;24:81-90.

49. Haynes RD, Sackett D, Taylor D. Increased absenteeism from work after detection and labeling of hypertensive patients. N Engl J Med 1978;299:741-4.

50. Havas S, Reisman J, Hsu L, Koumjjian L. Does cholesterol screening result in negative labeling effects? Arch Intern Med 1991;151:113-9.

51. Lefebvre RC, Hursey KG, Carleton RA. Labelling of participants in high blood pressure screening programs, implications for blood cholesterol screenings. Arch Intern Med 1988;148:1993-7.

52. McCann J, Stockton D, Godward S. Impact of false-positive mammography on subsequent screening attendance and risk of cancer. Breast Cancer Res 2002;4:R11.

53. Caruso A, Efficace F, Parrila A, Angelone L, Ferranti F, Grandinetti ML. [Pain and anxiety related to mammography in 
breast cancer patients. Psychological evaluation in an experimental study]. Radiol Med (Torino) 2001;102:335-9.

54. Seppa N. Cancer tests can heighten anxiety. Sci News 1998;154:316.

55. Feeny D, Furlong W, Boyle M, Torrance GW. Multi-attribute health status classification systems: Health Utilities Index. Pharmacoeconomics 1995; 7:490-502.

55. Kaplan RM, Anderson JP. A general health policy model: Update and applications. Health Serv Res 1988;23:203-35.

57. Kaplan RM, Anderson JP, Wu AW, Mathews C, Kozin F, Orenstein D. The Quality of Well-Being Scale. Applications in AIDS, cystic fibrosis, and arthritis. Med Care 1989;27(Suppl 3):S27-43.

58. Torrance GW, Furlong W, Feeny D, Boyle M. Multi-attribute preference functions: Health Utilities Index. Pharmacoeconomics 1995;7:503-20.

59. Krahn M, Ritvo P, Irvine J, et al. Patient and community preferences for outcomes in prostate cancer: implications for clinical policy. Med Care 2003;41:153-64.

60. Mohide EA, Torrance GW, Streiner DL, Pringle DM, Gilbert R. Measuring the well being of family caregivers using the time trade-off technique. J Clin Epidemiol 1988;41:475-82.
61. Revicki DA, Leidy NK, Brennan-Diemer F, Thompson C, Togias A. Development and preliminary validation of the multiattribute Rhinitis Symptom Utility Index. Qual Life Res 1998;7:693-702.

62. Revicki DA, Leidy NK, Brennan-Diemer F, Sorensen S, Togias A. Integrating patient preferences into health outcomes assessment: The multiattribute Asthma Symptom Utility Index. Chest 1998;114:998-1007.

63. Fahs MC, Mandelblatt J, Schechter C, Muller C. Cost effectiveness of cervical cancer screening for the elderly. Ann Intern Med 1992;17:520-7.

64. Eddy DM. The value of mammography screening in women under age 50 years. JAMA 1988;259:1512-9.

65. Eddy DM. Screening for breast cancer. Ann Intern Med 1989;111:389-99.

66. Coley CM, Barry MJ, Fleming C, Fahs MC, Mulley AG. Early detection of prostate cancer. Part II: Estimating the risks, benefits, and costs. Ann Intern Med 1997;126:468-79.

67. Loss RW, Hall WJ, Speers DM. Evaluation of early airway disease in smokers: Cost effectiveness of pulmonary function testing. Am J Med Sci 1979;278:27-37. 


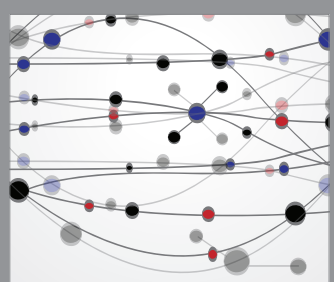

The Scientific World Journal
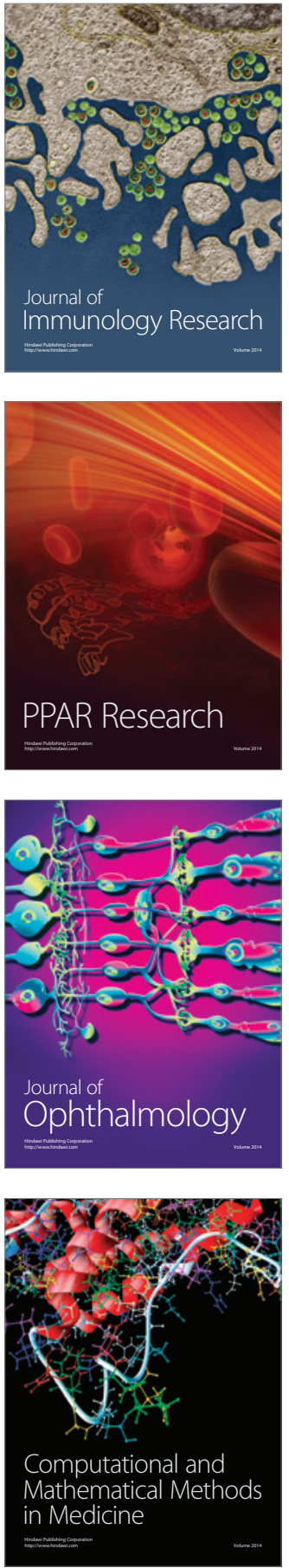

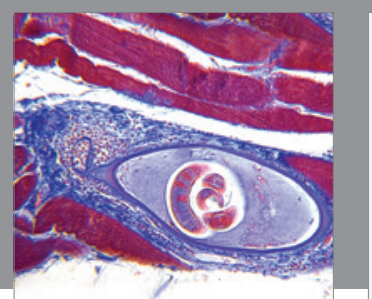

Gastroenterology Research and Practice

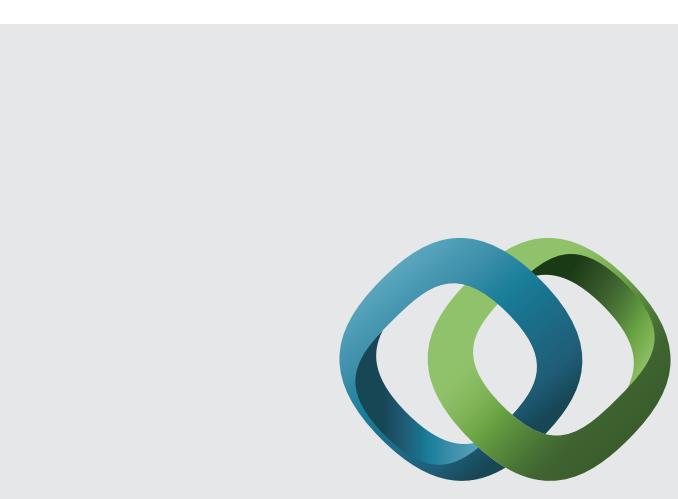

\section{Hindawi}

Submit your manuscripts at

http://www.hindawi.com
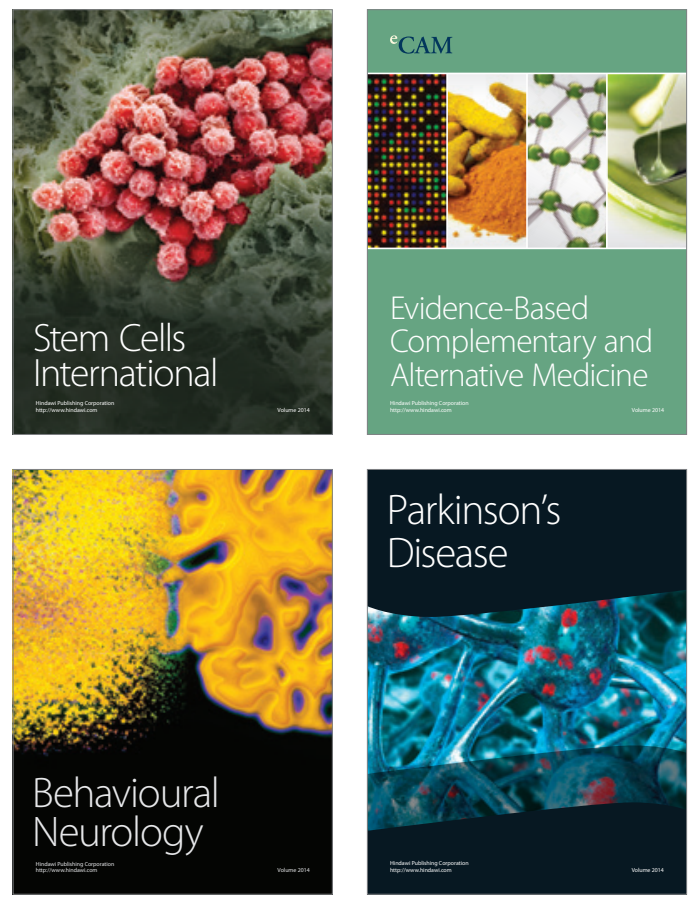
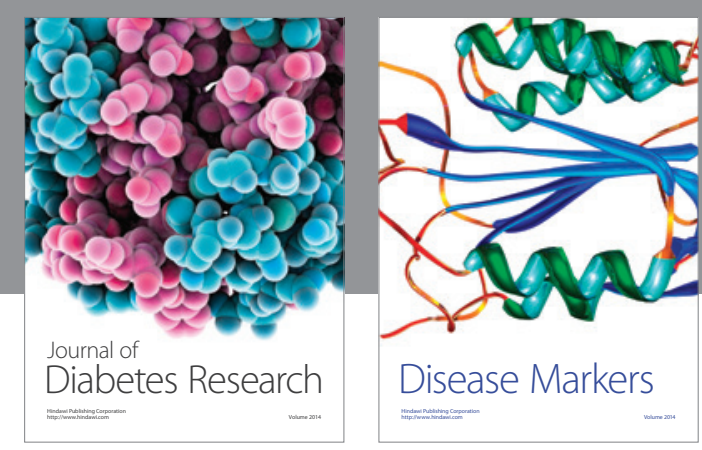

Disease Markers
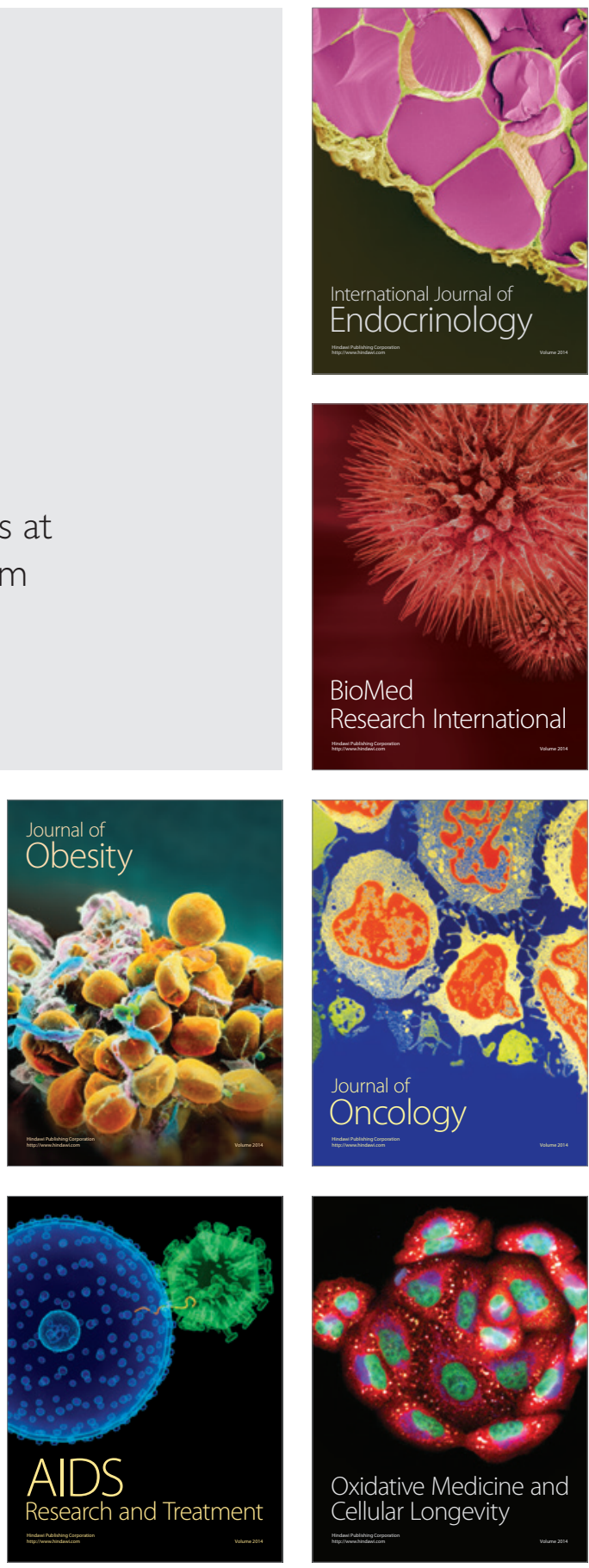